Economía, Sociedad y Territorio, vol. vIII, núm. 26, 2008, 477-515

\title{
Políticas ambientales-forestales y capital social femenino mazahua
}

\author{
Silvana LARA-ALDAVE \\ IVONNE VIZCARRA-BORDI*
}

\begin{abstract}
The aim of this paper is to understand how the concepts of social capital and gender perspective were included in the environmental forest policies during the presidency of Vicente Fox in Mexico. We analyse their performance in different local contexts. Our hypothesis is that this inclusion responds more to worldwide and national interest rather than to the local needs and its reality. We use institutional ethnography to analyse the replication of discursive practices about the inclusion of the gender perspective in environmental policies. We show how this creates the need for institutional intervention to solve problems generated in the global sphe$r e$. These mechanisms are exemplified with the case of Mazahua women in two forest communities in the Mazahua zone of the State of Mexico.
\end{abstract}

Keywords: social capital, gender, forest policies, Mazahuas, institutional ethnography.

\section{Resumen}

El objetivo del artículo es conocer cómo se incluyó el concepto de capital social y la perspectiva de género en el diseño de las políticas ambientales forestales del gobierno de Vicente Fox en México y cómo operaron sus mecanismos de ejecución en contextos locales. La hipótesis es que dicha inclusión corresponde más a intereses mundiales y nacionales que a necesidades y realidades locales. Se recurre a la etnografía institucional para analizar la reproducción de prácticas discursivas sobre la inclusión de la perspectiva de género en las políticas ambientales, y cómo se crean necesidades de intervención institucional para resolver problemas formulados en ámbitos globales. Se presenta como ejemplo el movimiento de mujeres mazahuas en dos comunidades con áreas boscosas de la zona mazahua del Estado de México.

Palabras clave: capital social, género, políticas forestales, mazahuas, etnografía institucional.

* Universidad Autónoma del Estado de México. Correos-e: silvanalara67@yahoo. com.mx, silvanalara67@hotmail.come ivbordi@yahoo.com.mx, ivbordi@hotmail.com, ivb@uaemex.mx 


\section{Introducción $^{1}$}

Sin duda, el deterioro ambiental es un tema prioritario y presente en todas las agendas de desarrollo en el ámbito mundial. Dentro de las agendas sobre ambiente y desarrollo sostenible ${ }^{2}$ se consideraron los temas de agua y forestal como recursos estratégicos de seguridad nacional. De aquí que entre las preocupaciones mundiales destaque el detener y contrarrestar las altas tasas de deforestación prevalecientes en los países vulnerables, es decir, en aquéllos que no tienen capacidad de respuesta institucional y legal para controlar sosteniblemente el manejo de sus recursos forestales, como sucede en algunos países de Asia, África del Sur y América Latina (faO, 2005). Pese a que en México se hacen esfuerzos legales e institucionales para alcanzar un mejor uso, manejo, aprovechamiento y conservación más racional de los bosques y las selvas, la ejecución de los programas derivados de la Ley General de Desarrollo Forestal Sostenible (LGDFS) ${ }^{3}$ se enfrentan a esquemas locales y regionales tradicionales en el manejo de recursos que entorpecen que se lleven a cabo. Para asegurar la eficiencia de éstos, organismos internacionales (вм, 2001a; PNUD, 2000a, 2000 b; CEPAL, 2003) propusieron promover y evaluar el capital social de localidades que sufren problemas de deterioro ambiental y que podrían, de alguna manera, responder positivamente a los programas para mejorar su calidad de vida, así como la sostenibilidad del medio ambiente (Lechner, 2000). Junto con esta propuesta, converge de manera paralela la preocupación mundial por incorporar la perspectiva de género en las políticas públicas ambientales (ONU, 1992).

Con el fin de acceder a los recursos financieros internacionales etiquetados para la conservación y protección de áreas natu-

\footnotetext{
${ }^{1}$ Este trabajo es resultado del proyecto de investigación "Estudio de las políticas foxistas en materia de seguridad alimentaria en comunidades mazahuas, desde una perspectiva de género, fase I", financiado por el Conacyt mexicano, clave 36080.

${ }^{2}$ En este trabajo no profundizaremos en el debate conceptual de desarrollo sostenible y sus implicaciones en países, regiones, comunidades e individuos. Simplemente nos referiremos a él en términos de práctica discursiva difundida por las agencias de desarrollo, en conferencias mundiales y en políticas ambientales internacionales, nacionales y estatales. Al igual que no se hace diferencia entre los términos sostenible y sostenible en estos discursos, aquí se respetan sus usos políticos y discursivos.

${ }^{3}$ Esta ley, publicada en el Diario Oficial de la federación el 25 de febrero de 2003 y puesta en práctica el 26 de mayo del mismo año, sustituye a la de 1992 con el fin de crear un nuevo modelo forestal que dé opciones de desarrollo sostenible y responda a las debilidades institucionales que no han podido resolver situaciones de emergencia, como la pobreza y la marginación en que viven más de 12 millones de mexicanos que habitan regiones forestales (Semarnat, 2003).
} 
rales que se encuentran en procesos de deterioro, la política ambiental mexicana, al menos en sus discursos, reconsideró diseñar sus programas tomando en cuenta tanto el capital social local como la incorporación de las mujeres a dichos programas. De aquí que el gobierno del presidente Vicente Fox (2000-2006) haya puesto en marcha el Programa de Equidad de Género, Medio Ambiente y Sostenibilidad, Progemas 2002-2006 (Semarnat, 2004). El objetivo del trabajo que aquí presentamos es dar a conocer cómo se incluyó el concepto de capital social y la perspectiva de género en el diseño de las políticas ambientales forestales durante el periodo mencionado y cómo operaron sus mecanismos de ejecución en contextos locales. Partimos de la hipótesis de que su inclusión corresponde más a intereses mundiales y nacionales y no tanto a las necesidades y realidades locales, pues cuando estas políticas se ejecutan en contextos específicos generan resultados imprevistos del objetivo inicial, sobre la idea de que a mayor capital social femenino más éxito en la inclusión de las mujeres al desarrollo sostenible y, por tanto, una mejora sustancial en las condiciones de vida de éstas, su familia y las comunidades.

Incorporar las dos vertientes -capital social y género- al diseño e instrumentación de los programas ambientales implica varios problemas no sólo de orden institucional y cultural, también conceptual, lo que deriva en serias dificultades para ejecutar el programa. Por un lado, la noción de capital social tiene diversas connotaciones teóricas, que de alguna manera se aprehenden y adaptan en políticas para el desarrollo sostenible, de forma que la preocupación institucional se centra en cómo medir el capital social para predecir a priori la eficiencia y eficacia de su intervención. En este sentido, el capital social se entiende "como un atributo de los individuos y sus relaciones, que fortalece su capacidad para resolver problemas de acción colectiva. El capital social representa un valor básico para el desarrollo y conservación del capital comunitario, natural o construido, físico o humano" (Merino, 2004: 129). Esta acotada definición deja de lado otras formas de organización comunal basadas en la división sexual del trabajo, en los sistemas de cargos, en la integración a mercados laborales nacionales e internacionales y otras formas organizativas de las comunidades rurales e indígenas que estructuran su identidad (Nahmad, 2001). Dada la complejidad para acercarse a medir en estos términos el capital social, parece que las instituciones gubernamentales prefieren adecuarse a los térmi- 
nos provenientes de los intereses de organismos internacionales por encima de los que ofrecen los científicos sociales.

Por otro lado, los pocos estudios sobre género y bosques demuestran que gran parte de las mujeres mexicanas que habitan en zonas forestales o dependen de ellas, no tienen acceso ni control sobre estos recursos. El estudio de Arizpe et al. (1993) indica, por ejemplo, que las diferentes percepciones que tienen las mujeres respecto de los hombres sobre la deforestación en la Selva Lacandona, se basan sobre todo en los usos específicos de los recursos según el sexo. Velázquez $(1996,1997,2005)$ por su parte, de manera reiterada señala que el uso y manejo de los recursos forestales de las selvas y bosques tropicales mexicanos, en particular de la zona maya, están determinados por las relaciones de género socialmente construidas en las comunidades forestales, donde las mujeres ven reducidas las posibilidades de subsistencia familiar debido a su limitado acceso a lo recursos, mientras que para los hombres es menos factible explotar los recursos maderables cuando sus comunidades quedan ubicadas en áreas naturales protegidas. El estudio de Vázquez (2002) apunta hacia la desigualdad cultural de los géneros como mecanismo que regula el acceso y control sobre los recursos críticos para la subsistencia familiar en la zona de protección forestal de Los Tuxtlas. Mecanismos que se basan principalmente en la legitimación de la posesión de la tierra, donde los hombres tienen claras ventajas.

El gran reto de la política ambiental-forestal estriba, por tanto, en desarrollar un programa que asegure la equidad entre los géneros, tomando en consideración que las relaciones de poder se reproducen jerárquica y asimétricamente entre hombres y mujeres, donde ellas son las más afectadas en cuanto al acceso, manejo y control de los recursos forestales. ${ }^{4}$ Aunque algunas comunidades han demostrado que tienen mayor capacidad de organización social para responder, adecuar y aplicar proyectos, programas y políticas que atiendan sus demandas específicas, si no se consideran las construcciones sociales que regulan las relaciones de género, las acciones a favor de la población femenina

\footnotetext{
${ }^{4}$ Se entiende por recurso forestal "la vegetación forestal, natural, artificial o inducida, sus productos y residuos, así como los suelos de los terrenos forestales o de aptitud preferentemente forestal". Como manejo forestal se entiende el "conjunto de acciones y procedimientos que tienen por objeto el cultivo, protección, conservación, restauración o aprovechamiento de los recursos forestales, de tal manera que se respete la integridad funcional y las capacidades de carga de los ecosistemas a los que se integran" (FAO, 1997: 1-2).
} 
en los programas ambientales corren el peligro de quedarse en un nivel discursivo y de buenas intenciones gubernamentales.

La etnografía institucional es la metodología cualitativa que nos permite, precisamente, confrontar ambas arenas: los intereses institucionales y las realidades locales. Por un lado, se contextualizan y analizan los discursos, dentro de los cuales se establecen las relaciones y negociaciones entre al menos dos y en general más sujetos (instituciones), conscientes y políticamente significantes en las intervenciones y entre los arreglos institucionales para resolver los problemas socialmente construidos (Clifford, 2000).

Por otro lado, a través de tres formas de interpretación de las relaciones institucionales (mundial, nacional y local o regional), se observa que la necesidad de promover el capital social e incorporar la perspectiva de género en las políticas públicas ambientales y forestales, corresponde más a la reproducción de prácticas discursivas del desarrollo sostenible ${ }^{5}$ que al conocimiento real de las demandas específicas de las mujeres rurales e indígenas que habitan en comunidades con serios problemas de degradación ambiental, específicamente relacionados con la deforestación.

Con la ayuda de la etnografía institucional se "abre la posibilidad de que exista mucho más detrás de los proyectos de desarrollo. [...] Si estos discernimientos se hacen más visibles para los actores de los proyectos, es posible que se aprenda más acerca del progreso y potencial de estos últimos [...] sugiere que entre los diferentes actores participantes pueden coexistir múltiples realidades al interior de un proyecto, cuyo reconocimiento puede ayudar a explicar las diferentes motivaciones para involucrarse en ellos" (Lewis, 2001: 360-361). En este sentido, nos basamos en la propuesta de Ferguson (1990) que observa cómo y bajo qué intereses se justifica la intervención de un proyecto, intereses que no necesariamente corresponden a las demandas sociales reales de una localidad o grupo, sino más bien se justifican en la necesidad de contar con agencias de desarrollo que finalmente intervienen en la vida social y económica de la población beneficiada.

En la segunda parte se interpreta y analiza el conocimiento que sobre género y capital social tienen los funcionarios nacio-

${ }^{5}$ Apoyadas en la idea de que el desarrollo sostenible es una extensión del paradigma del desarrollo. Esta idea propuesta por Escobar (1995) se refiere a una nueva etapa de desarrollo que pone a disposición del poder nuevas clientelas, haciéndolas visibles y responsables, al incluirlas en programas de desarrollo sostenible. Estas clientelas son: la naturaleza en su dimensión ecológica (protección y conservación de los recursos naturales), el saber local de las comunidades indígenas, las mujeres y los campesinos. 
nales, estatales y locales encargados de diseñar y ejecutar las políticas ambientales y forestales de la Comisión Nacional Forestal (Conafor), de la Secretaría del Medio Ambiente y Recursos Naturales (Semarnat); funcionarios de Protectora de Bosques (Probosque) y de la Comisión Estatal de Parques Naturales y de la Fauna (Cepanaf) de la Secretaría de Ecología del Estado de México; de la Secretaría de Desarrollo Agropecuario del Estado de México (Sedagro), así como de los regidores municipales encargados de la ecología y el desarrollo social.

En la tercera parte se presentan tres casos de estudio cuya finalidad es analizar, en los flujos de intervención institucional, las dificultades para incluir la perspectiva de género y el capital social en programas de manejo forestal. En este apartado se hace referencia al caso del movimiento indígena de mujeres mazahuas en defensa de sus recursos naturales, para diferenciar las respuestas de otras mujeres que, con distinto tipo de organización, se relacionan con políticas forestales. Para tal efecto, se escogieron dos comunidades de la región noroeste del Estado de México, cuyos bosques son parte de la Sierra Madre Occidental y presentan bastas zonas de deforestación.

Los criterios de selección de estas comunidades se basaron en información otorgada por la Conafor (delegación estatal) y Probosque sobre proyectos forestales con perspectiva de género y que tuvieran un acuerdo interinstitucional entre los tres niveles de gobierno. Debido a que no tenían un proyecto específico y con estas características diseñado para mujeres, se nos recomendó visitar dos comunidades mazahuas que llevan acabo un proyecto de viveros sociales con el fin de aprovechar la mano de obra femenina. Por su parte, el Instituto Mexiquense de la Mujer (ahora Consejo Estatal de la Mujer y de Bienestar Social) nos sugirió visitar una comunidad que lleva a cabo proyectos de reforestación exitosos a cargo de mujeres.

De esta manera se seleccionaron las comunidades de La Mesa, municipio de San José del Rincón, cuya población es eminentemente mazahua; y Tapaxco, municipio de El Oro de Hidalgo, que pese a sus antecedentes mazahuas, hoy en día es prácticamente una comunidad mestiza. La primera forma parte del Área Natural Protegida de la Mariposa Monarca (ANPMM) y, por tanto, de interés o prioridad de política ambiental-forestal nacional y 
mundial. ${ }^{6}$ Como parte de ese interés, en La Mesa se llevan a cabo varios proyectos forestales, de conservación y ecoturísticos entre los que destaca un vivero social de planta forestal. En tanto que la segunda comunidad -pese a la sobreexplotación de sus bosques y la considerable reducción su área forestal- resulta no tener prioridad política porque no forma parte de alguna área natural protegida. El único programa que llega año con año es el de reforestación.

A través de entrevistas semiestructuradas y de la observación, logramos conocer la opinión de 22 mujeres y ocho hombres de ambas comunidades respecto de la operación de los dos programas y su relación con el uso y manejo forestal de sus comunidades.

\section{Discursos dominantes: capital social, género y medio ambiente}

El término desarrollo sostenible apareció por vez primera en 1987 en el informe de la Comisión Mundial para el Medio Ambiente -también llamada Comisión Brundtland-, que es una prolongación de la Declaración de Estocolmo de 1972, con el fin de establecer socios mundiales para la reciente base de la equidad a partir de nuevos lazos de cooperación internacional entre los Estados, los sectores claves de la sociedad y los pueblos (ONU, 1992).

De este informe se desprende la siguiente definición: "El desarrollo sostenible es aquel desarrollo que satisface las necesidades de las generaciones presentes sin comprometer la habilidad de las futuras para satisfacer sus propias necesidades" (Brundtland, 1987), término que se retomó y debatió en la Cumbre de la Tierra en Río de Janeiro en 1992. A partir de entonces y hasta la reunión de Johannesburgo, Sudáfrica, en 2002, en las agendas internacionales se refleja la creciente preocupación mundial por los daños ecológicos causados por el gran desarrollo económico

\footnotetext{
${ }^{6}$ El Fondo Mundial para la Naturaleza (WWF, por sus siglas en inglés) y el Fondo Mexicano para la Conservación de la Naturaleza (FMCN) apoyan el ANPMM a través del Fondo para la Conservación de la Mariposa Monarca (FM) mediante un esquema de incentivos económicos para propietarios de tierras en la zona núcleo de la reserva que conserven sus bosques. Entre 2001 y 2004 el FM reunió 6.5 millones de dólares (cinco millones de una fundación estadounidense, un millón del gobierno mexicano y 250 mil dólares de cada uno de los estados de México y Michoacán) con los cuales ha apoyado, con aproximadamente un millón de dólares, a 31 ejidos, comunidades indígenas y pequeñas propiedades para fomentar la conservación en 9,089 hectáreas de la zona núcleo de la reserva (WWF México Bosques fondos extranjeros disponible en línea: http://www.wwf.org.mx/wwfmex/descargas/FM_Rep_Monitoreo_Forestal.pdf (recuperado en $12 / 05 / 2005)$.
} 
y una fuerte desigualdad social. Se reconoce que, si bien en algunas naciones existe voluntad y políticas para encausarlos, en la actualidad ningún país tiene un desarrollo sostenible de los recursos mientras se sigan explotando con el mismo fin: expandir los capitales. Asimismo, las propuestas de estas instancias apuntan a crear una conciencia de dimensiones planetarias, en todos y cada uno de los actores sociales, para evitar más pérdidas de recursos naturales que comprometen la vida de las generaciones futuras.

Junto a estas propuestas hay dos preocupaciones también de dimensión mundial: la búsqueda de opciones para aliviar la pobreza y la desigualdad de género. Lo que desde las ciencias sociales invita a la creatividad teórica y metodológica en todas sus áreas para generar conocimientos que posibiliten fortalecer las capacidades de las mujeres para participar individual y colectivamente en la toma de decisiones sobre el uso, manejo y control de los recursos mediante el acceso a la información, a los recursos financieros y a la capacitación técnica y económica, y de esta manera -como pretenden los organismos mundiales- darle viabilidad a su trabajo para elevar su capital social y sus formas de organización comunitaria en las políticas públicas ambientalesforestales (ONU, 2000).

\subsection{Capital social}

La noción de capital social proviene de las propuestas teóricas de Bourdieu (1986), Coleman (1990) y Putnam (1993). Estos autores elaboraron diferentes marcos teóricos que convergen en la construcción de una ciencia general de la economía de las prácticas que trata el intercambio mercantil como una forma más de reciprocidad con capacidad para identificar cómo las distintas formas de capital se transforman en otras (Bourdieu, 1986). Entendido así, el capital (en todas su formas) equivale al poder y su contribución configura la estructura social fundada en el individualismo metodológico y en el principio de acción racional (Coleman, 1990).

De acuerdo con Bourdieu (1986), las redes de relaciones son producto de estrategias de inversión, individuales o colectivas, conscientes o inconscientes, que buscan establecer o reproducir relaciones aprovechables en el corto o largo plazos. Para Coleman (1990), el concepto de capital social es el valor de esos aspectos o recursos necesarios que facilitan ciertas acciones indi- 
viduales de quienes forman las estructuras sociales. Asimismo, este autor señala que el capital social es un bien público en el sentido de que sus beneficios no sólo los captan los actores que participan en una determinada relación social, sino también otros.

Dada la complejidad del concepto, autores como Putnam (1993) y Durston (1999) ayudan a comprender por qué organismos internacionales lo utilizan constantemente, sobre todo Putnam, quien pone el acento en la participación social como riqueza y fortaleza del tejido social interno de una sociedad, idea que coincide con los intereses de la promoción del buen gobierno del Banco Mundial (вм), del Banco Interamericano del Desarrollo (BID), de la Comisión Económica para América Latina (CEPAL) y del propio Programa de las Naciones Unidas para el Desarrollo (PNUD). De esta manera, Putnam (1993) maneja tres componentes esenciales del capital social: 1) grado de confianza entre los actores sociales; 2) normas de comportamiento cívico practicadas; y 3) niveles de asociatividad para actuar cooperativamente. Estos componentes de alguna manera coinciden con la propuesta de Durston quien define el capital social como "el conjunto de normas, instituciones y organizaciones que promueven la confianza y la cooperación entre las personas, en las comunidades y en la sociedad en su conjunto" (1999: 103). En ambas formulaciones el capital social se concentra en sus manifestaciones colectivas y plantea que las relaciones estables de confianza y cooperación pueden reducir los costos de transacción, producir bienes públicos y facilitar que se constituyan actores sociales o, incluso, sociedades civiles saludables.

Estos componentes de alguna manera se incorporan en los discursos del BID (2001), en los que se agregan, además, los valores éticos y la cultura entendida como la manera de vivir juntos. Asimismo, el PNUD (2000b: 13) destaca que un factor decisivo en el desarrollo del capital social es el marco institucional regulado tanto por la organización social como por las políticas públicas; es decir, la regulación de la asociatividad se da en organizaciones formales y en relaciones informales de confianza y cooperación. De igual modo, la CEPAL considera que el capital social es el "conjunto de relaciones sociales basadas en la confianza y los comportamientos de cooperación y reciprocidad" social (2003: 13). Por su lado, el BM define el capital social en términos de sus propios intereses de intervención, de aquí que se refiera "a las instituciones, relaciones y normas que conforman la calidad y cantidad de las interacciones sociales de una sociedad. Numerosos 
estudios demuestran que la cohesión social es un factor crítico para que las sociedades prosperen económicamente y para que el desarrollo sea sostenible. El capital social no es sólo la suma de las instituciones que configuran una sociedad, sino que es asimismo la materia que las mantiene juntas" (2001a: 1). Nelson Acosta (2002) señala que el conjunto de estos componentes finalmente se convierten en prerrequisitos necesarios para el proceso de desarrollo. Dado que el capital social no sólo se refiere a la cohesión social sino a las potencialidades que tiene una sociedad para participar en el mejoramiento de su calidad de vida y de su desarrollo, los lazos de solidaridad y unión se traducen en la capacidad para proyectar el desarrollo (Cemapem, 2004: 14).

Uno de los problemas que afrontan estos organismos es su afán por medir el capital social para justificar su intervención para elevarlo o constituirlo. En consecuencia, en la actualidad esto ha llevado a algunos investigadores a recopilar índices con elementos aproximados, los cuales resultan problemáticos para medir las propiedades con conceptos ambiguos como comunidad, red y organización, sobre todo si se trata de sociedades étnicas con construcciones sociales, tradicionales, modernas, híbridas y/o complejas. De ahí que el concepto de capital social desde la lectura étnica, o más bien antropológica, que apunta Salomón Nahmad:.

\begin{abstract}
...pasa por un balance entre: 1) la habilidad para sobrevivir económica y culturalmente; y 2) la capacidad de crear mecanismos políticos de lucha, resistencia y ajuste a una sociedad y a un proyecto nacional. Sin embargo, la tensión aludida entre pueblos indígenas y estructuras hegemónicas, coloca al capital social indígena en una relación de subordinación, por lo que se desarrolla con un alto grado de vulnerabilidad. En ese sentido, es necesario considerar un tercer elemento de análisis del capital social indígena, a saber: 3) los efectos que las estructuras hegemónicas tienen en el debilitamiento del capital social indígena y su transformación en nuevas expresiones del capital social o incluso en la pérdida y ausencia de formas de capital social (2001: 2).
\end{abstract}

Estos elementos son ignorados por los organismos internacionales de desarrollo (humano, social, sostenible y económico) porque sus agendas se basan más en las competencias globales que en las demandas sociales reales, donde "el Estado depende de la estabilidad social y el apoyo popular para mejorar las perspectivas económicas y sociales de las comunidades y naciones como: mejorar la educación y los servicios de salud, construir instituciones políticas competentes y responsables y facilitar la 
aparición de mercados libres capaces de competir en la economía global” (BM, 2001b: 2).

Ciertamente, el concepto de capital social también juega un rol muy importante en las políticas ambientales sobre manejo de recursos naturales, pues como apunta Leticia Merino, este concepto "permite a las comunidades la construcción de instituciones para el manejo de este tipo de recursos comunes naturales como son los bosques" (2004: 130) y, por tanto, da la oportunidad de entrelazarlo con el capital natural (constituido por la dotación de recursos naturales con que cuenta una nación) y el desarrollo para lograr la protección y conservación de los recursos forestales.

Bajo este interés, el capital social se debe entender como "las capacidades organizativas de la sociedad rural e indígena, las relaciones internas entre estos grupos y sus organizaciones, así como sus relaciones con la sociedad civil y con las instituciones del Estado" (Nahmad, 2001: 2), las cuales varían considerablemente según el género. Sin estas consideraciones, difícilmente las intervenciones institucionales promoverán el bienestar común y su armonía con el medio ambiente.

\subsection{Género y medio ambiente}

Actualmente, la literatura sobre la problemática ambiental señala a las mujeres no sólo como víctimas de los fenómenos ambientales, también subrayan la importancia de su participación para resolver la actual crisis ambiental del planeta, lo que hace imperativa la necesidad de investigación ambiental con perspectiva de género (Velázquez, 1996). De aquí surgieron diversas posturas teóricas y políticas feministas para abordar el binomio construido socialmente sobre mujer-naturaleza, el cual constriñe la posibilidad de relacionar a las mujeres con acciones afirmativas individuales y colectivas en beneficio de la sociedad (Braidotti et al., 1994). El ecofeminismo, por ejemplo, supone que la racionalidad basada en un marco teórico dualista es un problema en las propuestas hechas por mujeres (MacKenzie et al., 1984), porque sugiere dominación y diferenciación (Birke 1986). Por su parte, Vandana Shiva (1988) propone al ecofeminismo como una alternativa teórica para evitar la inferioridad y subordinación al patriarcado hegemónico de categorías analíticas, como la naturaleza y las mujeres. Esta postura se ha criticado fuertemente por su esencialismo (Vizcarra, 2005), pero dio pie para cons- 
truir nuevas teorías como la ecología política feminista propuesta por Rocheleau y sus colaboradoras (1996), que pretende acotar las distancias entre la teoría y la experiencia práctica. De esta manera, la propuesta considera que "los saberes femeninos conjugados con los múltiples papeles de las mujeres como productoras, reproductoras y consumidoras, han orillado a las mujeres a crear y mantener habilidades integrativas con los sistemas complejos del hogar, de la comunidad y de su medio ambiente" (Vizcarra, 2005: 519).

En el ámbito mundial, los discursos sobre género y medio ambiente retoman sin lugar a dudas estas capacidades femeninas, pero sin que las demandas reales sean escuchadas. Es decir, difunden la idea de que, por naturaleza, las mujeres cuidan mejor el ambiente porque de este cuidado depende la subsistencia familiar y comunal. Por ejemplo, hasta mediados de los años ochenta, las mujeres que dependían de la leña para cumplir con sus responsabilidades hacia la familia, eran vistas como las principales destructoras de los bosques. Con la propuesta hecha en la Segunda Conferencia Internacional sobre la Mujer, en Nairobi 1985, se promovió un nuevo enfoque para eliminar todas las formas de discriminación hacia las mujeres y atribuirles diferentes grados de independencia económica: Mujeres en el Desarrollo (MED). En esta nueva era del feminismo, estas mujeres pasaron de ser destructoras del bosque a víctimas del desarrollo por su falta de acceso a los recursos naturales (Leach et al., 1995). Además, en dicha conferencia se subrayó el potencial del papel de las mujeres como administradoras de los recursos ambientales, su vulnerabilidad al cambio ambiental debido a su fuerte dependencia de los recursos ambientales y al hecho de que las iniciativas sobre desarrollo y medio ambiente necesitan apoyar las contribuciones de las mujeres (Paolisso, 1996).

Esta propuesta tuvo gran influencia en los compromisos adquiridos en la Conferencia de las Naciones Unidas sobre el Medio Ambiente y el Desarrollo (Río de Janeiro, 1992), donde se retoman los lineamientos de la Agenda 21 respecto de la participación de la mujer en la ordenación nacional de los ecosistemas y la lucha contra la degradación del medio ambiente, la eliminación de la discriminación por motivos de género y en garantizar el acceso de la mujer a los recursos (tierra y otros) así como a la educación y el empleo seguro (Semarnat, 1999).

Pese a que en el capítulo 24, "Medidas mundiales a favor de la mujer para un desarrollo sostenible y equitativo", de la Agenda 
21 tratan a las mujeres como un grupo vulnerable y sabiendo que ellas participan activamente en los movimientos ambientalistas, sus posturas y reclamos siguen vigentes hasta la última reunión de Johannesburgo (2002), aun cuando en la Cuarta Conferencia Mundial se formuló el capítulo K de la Plataforma de Acción de Pekín (1995). Los reclamos se centran en que las mujeres todavía no participan en la toma de decisiones y tampoco se han respetado los acuerdos a que se comprometieron los Estados (ONU, 1992, 2000):

- Lograr la participación de mujeres en todos los niveles de toma de decisiones relativas al ambiente, incluyendo la ordenación de los ecosistemas, y en la lucha contra la degradación ambiental.

- Aumentar el número de mujeres en puestos de toma de decisiones sobre medio ambiente y desarrollo.

- Integrar la perspectiva de género en las políticas y programas a favor de un desarrollo sostenible.

- Establecer mecanismos para evaluar los avances en políticas ambientales y de desarrollo sobre mujeres y velar para que éstas contribuyan y participen en ellas.

- Considerar la posibilidad de programas que eliminen obstáculos que impiden la plena participación de la mujer en el desarrollo sostenible y la vida pública.

Estos ejes estratégicos provienen de las propuestas de Género en el Desarrollo (GED), donde se emplea la construcción de género como el punto clave para mediatizar las relaciones entre mujeres y hombres con el medio ambiente, convirtiéndolas en agentes de cambio. En este sentido, las posturas de MED quedan rebasadas, pues el ejercicio de empoderamiento económico centrado sólo en las mujeres ignoró que las formas de subordinación y discriminación en el acceso, uso, manejo y control de los recursos naturales se deben a las relaciones de género que persisten en diferentes sociedades que generalmente son jerárquicas, asimétricas y se perpetúan en las instituciones modernas y patriarcales, poniendo casi siempre en desventaja a las mujeres (Agarwal, 1994; Leach et al., 1995; Rocheleau et al., 1996). Estos aspectos demuestran que la relación mujeres-medio ambiente es compleja, pues en una región de desigualdades sociales y de género $-\mathrm{y}$ en un contexto de dominio neoliberal- las mujeres pobres, indígenas o campesinas se ven obligadas a luchar por la 
supervivencia, casi siempre lejos de las preocupaciones ambientales, pero al mismo tiempo sufren en sus vidas cotidianas los efectos del deterioro ecológico y las relaciones de género, donde el poder masculino es el que domina estos espacios.

De acuerdo con Verónica Vázquez, las políticas ambientales enmarcadas en el desarrollo sostenible para resolver problemas de degradación ambiental, debe considerar soluciones integrales con otros sectores para problemas de pobreza, desigualdad social y de género, "y apuntar a formas eficientes de resolver la distribución desigual de poder y riqueza entre naciones, regiones, comunidades y géneros. [...] ir más allá del discurso político dominante, que no da razón del trabajo de las mujeres y el impacto de las actividades económicas en el medio ambiente" (1999: 27).

Por lo anterior, el capital social femenino se puede definir como la habilidad de las mujeres para sobrevivir económica y culturalmente, con base en sus capacidades tanto en los mecanismos de lucha y resistencia ante las relaciones de poder que legitiman una desigualdad social en la distribución de los recursos necesarios para su subsistencia, como en las formas de solidaridad o confianza que ellas establecen para organizarse entre sí y responder a las adversidades políticas, socioeconómicas y ambientales.

\section{Etnografía institucional: género y política ambiental-forestal en México}

Una vez que se definió el concepto de capital social femenino como resultado del cruce epistemológico de género y capital social, la segunda fase de la etnografía institucional se basa en el estudio de cómo y en qué espacio social se problematiza la incorporación del género en la política ambiental-forestal, de forma que se justifique una cierta intervención institucional. Esta parte de la etnografía es fundamental para entender las políticas públicas, no sólo porque en ellas se determina el diseño y la instrumentación de los mecanismos de ejecución de los programas y proyectos gubernamentales, sino porque en estas fases burocráticas se establecen las pautas que dirigirán el cambio social o las formas del control social sobre la población objetivo.

\subsection{La incorporación de género}

Como suceso relevante en la evolución de la política ambiental mexicana, y con el fin de articular las decisiones gubernamenta- 
les para alcanzar un desarrollo sostenible, en 1994 se creó la Secretaría de Medio Ambiente, Recursos Naturales y Pesca (Semarnap). Esta secretaría elaboró en 1999 una Declaración para la Equidad de Género que, a grandes rasgos, es un alto en el camino para hacer conciencia y construir una verdadera política ambiental con perspectiva de género, tomando como base el marco legal nacional y los compromisos y acuerdos internacionales firmados y ratificados.

Entre los acuerdos internacionales destacan: las Acciones de la Agenda 21, capítulo 24 (1992), sección K del capítulo v de la Plataforma de Acción derivada de la cuarta Conferencia Internacional de la Mujer en Pekín (1995); el Convenio sobre la Diversidad Biológica (1992) que reconoce el papel de las mujeres en la conservación y uso sostenible de los recursos naturales; y la Convención Internacional de Lucha contra la Desertificación (1994) que enfatiza la importante participación de las mujeres rurales en esta lucha (Salazar, 1999). En el marco jurídico nacional inciden los artículos $1^{\circ}$ y $4^{\circ}$ de la Constitución Política de los Estados Unidos Mexicanos donde se prohíbe toda discriminación motivada por el género, el derecho a la igualdad entre hombres y mujeres, así como el derecho a un medio ambiente adecuado para su desarrollo y bienestar; la Ley General de Equilibrio y Protección al Ambiente (1995) establece como un principio de la política ambiental que "las mujeres cumplen una importante función en la protección, preservación y aprovechamiento sostenible de los recursos naturales y en el desarrollo, y que su completa participación es esencial para el logro del desarrollo sostenible" (Semarnat, 2004: 5).

Aunado a lo anterior y gracias a la sensibilidad de la primera secretaria de Estado en este organismo, la doctora Julia Carabias -quien tomó la experiencia del Espacio de Mujer y Medio Ambiente (1991) para preparar la discusión del Foro Civil para Río 1992 y las propuestas de la Red de Género y Medio Ambiente (1998), ambas conformadas por organizaciones feministas civiles y académicas-, se realizaron enormes esfuerzos para contar con datos desagregados por sexo sobre los beneficiarios de los programas y proyectos ejecutados por la Semarnap. Con estos datos, investigaciones académicas e informes de organizaciones no gubernamentales (ONGs) se elaboró el Addendum al Pro- 
grama Nacional de la Mujer (Pronam) ${ }^{7}$ sobre Mujer y Medio Ambiente. Cuando la Semarnap se convirtió en Secretaria de Medio Ambiente y Recursos Naturales (Semarnat), con el gobierno del "cambio" del presidente Vicente Fox (2000-2006), se dio origen a la Unidad Coordinadora de Participación Ciudadana y Transparencia donde quedó adscrita la Dirección de Género y Medio Ambiente (ahora Coordinación de Equidad de Género). Con este esfuerzo institucional, de alguna manera se concretaron varias de las propuestas feministas en materia de política ambiental y equidad de género.

\subsection{El Programa de Género, Medio Ambiente y Sostenibilidad}

En el marco jurídico nacional, uno de los objetivos del Plan $\mathrm{Na}$ cional de Desarrollo 2001-2006 (PND), es "lograr la igualdad de los derechos y obligaciones entre géneros en el acceso, uso, manejo, aprovechamiento y conservación de los recursos naturales” (Semarnat, 2004: 24), lo rescató el Programa Nacional para la Igualdad de Oportunidades y no Discriminación contra las Mujeres (Proequidad), ${ }^{8}$ para que la UCAST elaborara el Programa de Género, Medio Ambiente y Sostenibilidad en el año 2004 (Progemas), por un lado para responder a las presiones internacionales y, por otro, por los propios antecedentes de las feministas ambientalistas mexicanas (civiles, políticas y académicas). ${ }^{9}$

Debido a que no es suficiente con cambiar las normas jurídicas para lograr la igualdad entre ambos sexos y que se requieren enormes esfuerzos gubernamentales para diseñar políticas públicas proactivas, antidiscriminatorias y afirmativas para detectar y corregir "los persistentes, sutiles y ocultos factores que ponen a las mujeres en desventaja frente a los hombres [como] reconocer que el sexismo es resultado de una historia y de una actitud cultural” (Lamas, 2006: 63-64), el Progemas planteó cuatro líneas estratégicas que deberían convertirse en acciones afirmativas en favor de la igualdad entre hombres y mujeres, respetando sus diferencias sexuales/género:

\footnotetext{
${ }^{7}$ Este programa se institucionalizó durante la gestión del presidente Ernesto Zedillo (1994-2000) y tuvo como antecedente la Comisión Nacional de la Mujer (Conmujer), organismo descentralizado de la Secretaría de Gobernación en el mismo periodo.

${ }^{8}$ Desarrollado por el primer Instituto Nacional de las Mujeres en México (Inmujer 2001-2006).

${ }^{9}$ El programa pretendía ser uno de los pilares de la nueva política ambiental mexicana tal y como se contempló en el Programa Nacional de Medio Ambiente y Recursos Naturales 2001-2006. Para ampliar la información sobre las mujeres mexicanas en los movimientos ambientalistas, véase Aranda (2005).
} 
- Transversalidad e institucionalización de la perspectiva de género para sensibilizar, a través de talleres, a los altos y medios mandos y demás funcionarios tanto de la propia Semarnat como de sus organismos descentralizados. ${ }^{10}$ Sin embargo, durante estos talleres se han encontrado serios obstáculos culturales relacionados con las construcciones sociales de género que dominan en las instituciones mexicanas.

En primera instancia, cuando no son obligados por un funcionario de alto mando para asistir a los talleres de sensibilización de perspectiva de género, envían a una mujer a capacitarse: "género es cuestión de mujeres". En general estas mujeres no intervienen en la toma de decisiones sobre el diseño, instrumentación y operación de los proyectos ambientales. Lo mismo sucede con las secretarías estatales encargadas de ecología y medio ambiente, que con frecuencia son invitadas a participar en el Comité Técnico de Enlaces de Género. ${ }^{11}$ "No hay una estrategia encaminada a esa equidad ni se han preocupado ni se ha promovido ni se ha inducido. Hay mujeres en algunas jefaturas de departamento, por ejemplo, la unidad jurídica está a cargo de una mujer, así como la contraloría interna, pero nada más, y a veces ellas van a los talleres de la Semarnat." 12

En segunda instancia, observamos que si bien los funcionarios reciben esta capacitación, en la práctica no incluyen acciones afirmativas en favor de la equidad de género, pues sus sesgos genéricos traducen las acciones en beneficio sólo para mujeres; actitud que evita entender que la diferencia entre hombres y mujeres produce inequidad y que si no se promueve un cambio en estas relaciones, persistirán la pobreza y las desigualdades sociales. "Si queremos pensar que el objetivo es atender a toda la población marginada y estos programas no tienen una calificación muy específica para hablar de género, se dirigen, insisto, a atacar los problemas más graves de marginación

\footnotetext{
${ }^{10}$ Como la Coordinación Nacional de Áreas Naturales Protegidas (ahora Comisión, Conanp), la Conafor y la Comisión Nacional del Agua (CNA).

${ }^{11}$ Los comités están integrados por un representante y un titular de cada una de las cinco regiones nacionales (noroeste, noreste, centro-occidente, centro y sureste), además de representantes de delegaciones federales y estatales y de las áreas sustantivas centrales.

${ }^{12}$ Entrevista realizada en abril de 2004 al director de Restauración Forestal de Probosque, Secretaría de Ecología del Estado de México.
} 
de las comunidades indígenas y campesinas, aunque no distingan mucho el aspecto de género."13

Con frecuencia observamos que los funcionarios de mandos medios (directores, subdirectores y jefes de departamento) son hombres, y aun cuando tomaron los talleres de sensibilización, no se comprometen a difundir la perspectiva de género y mucho menos a transversalizarla en sus áreas de influencia gubernamental, pese a que en el discurso lo tengan bien aprendido.

- Coordinación interinstitucional y cooperación internacional con el fin de potenciar las acciones sectoriales e interinstitucionales (federales, estatales y municipales) para construir la equidad de género, en vinculación con programas y proyectos regionales, nacionales e internacionales. ${ }^{14}$

En el caso del Estado de México, debido a la rivalidad partidista entre los gobiernos federal (del Partido de Acción Nacional, PAN) y estatal (del Partido Revolucionario Institucional, PRI), los mecanismos de coordinación institucional entre los tres niveles de gobierno sólo se limitan a buscar alternativas y oportunidades de financiamiento internacional para desarrollar proyectos específicos como la protección natural de ciertos recursos naturales. Ya que muchos de estos apoyos vienen etiquetados con los principios de equidad de género y sostenibilidad, una táctica para acceder a ellos es incorporar dichos principios en el diseño de los proyectos (que la mayoría de la veces realizan organismos federales como la Semarnat, la Conafor y la $\mathrm{CNA}$ ), pero cuando llegan a la fase de normatividad y ejecución por parte de los organismos estatales (como Probosque o la Comisión Estatal de Parques Naturales y de la Fauna, Cepanf), las mujeres se vuelven clientes de los programas y proyectos.

- Corresponsabilidad y participación social. Esta línea estratégica corresponde sobre todo a los principios rectores del buen gobierno. Es evidente que se requiere cada vez más ampliar la participación de grupos de mujeres en los órga-

${ }^{13}$ Entrevista con el coordinador de delegaciones de la Secretaría de Ecología del Estado de México, en junio de 2004.

${ }^{14}$ Como en los casos de proyectos para Proteger y Conservar la Mariposa Monarca, el programa del Mar de Cortés y el Corredor Biológico de Mesoamérica. 
nos consultivos y espacios de toma de decisiones tanto de la Semarnat como de los organismos descentralizados, desconcentrados y sus secretarías homólogas en el ámbito estatal y en las regidurías municipales.

Por parte del Estado de México, la Secretaría de Ecología fue dirigida por Arlette Trujillo en el periodo 19992005. Gracias a su activismo feminista, impulsó la participación laboral de mujeres en puestos de dirección de dicha secretaría. Pero aun con este interés, la equidad de género no se aseguró con la presencia femenina, pues no se consolidaron los mecanismos para garantizar que las demandas de mujeres y hombres se incluyeran en la definición de las políticas y programas. Uno de los obstáculos más importantes fue la definición misma de demanda social y ambiental de las comunidades y sus habitantes, que si bien se rigió bajo un esquema de participación ciudadana y social, la convocatoria ignoró los contextos de discriminación genérica de acceso desigual a los recursos y alta presión demográfica sobre ellos, así como las condiciones de migración transnacional masculina. De aquí que la participación de las mujeres se limitara sólo a responder las exigencias de los programas y proyectos ambientales y forestales. Estas interacciones pueden crear nuevas sujeciones o relaciones de poder que profundizan las inequidades de género ya existentes.

En este sentido, en el Progemas se señala la necesidad interinstitucional de promover el fortalecimiento de las capacidades organizativas de las mujeres rurales e indígenas; es decir, que para enriquecer el capital social femenino en cuestiones de gestión ambiental-forestal se deben privilegiar acciones afirmativas que minimicen las condiciones de inequidad.

No, no existe ninguno etiquetado para mujeres, todos [los programas] se van así; incluso nuestras reglas dicen que no va haber discriminación de credo, religión, raza, ni género; sin embargo, sí hemos visto que en algunas comunidades los hombres emigran y son las mujeres quienes casi siempre apoyan nuestros trabajos porque son las que están siempre en casa y pues es un dinero extra para ellas, el problema es cuando los hombres están, pues ahí si ya no contamos con ellas. ${ }^{15}$

${ }^{15}$ Entrevista con Dalia (técnica de reforestación de la Conafor, realizada en agosto de 2004). 
- Procesos de gestión ambiental y desarrollo sostenible con equidad de género. Básicamente, esta línea estratégica pretende dar preferencia a las demandas y solicitudes de grupos y organizaciones de mujeres (capital social femenino) vinculadas a los procesos de gestión ambiental prioritarios de la Semarnat, ya sea por medio de asesoría y apoyo a proyectos en el sector ambiental, o bien canalizando y dando seguimiento ante las instancias responsables estatales, delegacionales y municipales (Semarnat, 2004).

Como se mencionó en párrafos anteriores, los proyectos diseñados en instituciones gubernamentales y organismos internacionales, en general, no corresponden con las demanda reales de las mujeres, hombres y sus familias y comunidades. Por ello, conservar y preservar los componentes ambientales durante la ejecución de las prácticas de manejo forestal, son más un compromiso institucional por proteger los valores de los ecosistemas forestales -integrándolos a la producción de bienes y servicios del bosque- que una demanda social real y femenina. Demanda que se encuentra estrechamente relacionada con el deterioro de los ecosistemas que afecta tanto las actividades que por tradición realizan las mujeres en el ámbito rural (basadas en el aprovechamiento de la vida silvestre y en la recolección, administración, transformación, consumo y venta de productos forestales, no maderables, de uso comestible y medicinal), como las que deben llevar a cabo cuando los hombres emigran y abandonan temporal o definitivamente sus tierras y hogares (Velázquez y Merino, 1997).

\section{Políticas forestales en comunidades mazahuas}

En lengua náhuatl, mazahua significa "poseedores de venados o región de venados"; fauna que en la actualidad ya no existe ni en la remota memoria de sus pobladores. "Esta región ha sufrido severos cambios sociales y ambientales originados por la explotación de la raíz de zacatón y por las actividades agropecuarias desarrolladas en las haciendas durante el siglo XIX y hasta los años treinta del siglo xx. El acelerado cambio del paisaje ambiental no se da, sin embargo, con el reparto agrario sino con el retiro paulatino del Estado en materia de desarrollo agropecuario, en los últimos 20 años" (Vizcarra, 2002: 10). 
En la actualidad, doce municipios del norte y noroeste del Estado de México (de los 125 que conforman la entidad) concentran la gran mayoría de las comunidades con hablantes de lengua indígena mazahua (HLIM). Los HLIM representan 2.4\% del total de la población indígena del país, de éstos, $85.1 \%$ se concentran en el Estado de México, donde 53\% son mujeres. En estos municipios se encuentran San José del Rincón y El Oro de Hidalgo; ambos con importantes áreas forestales y cuya ubicación territorial es de interés político y estratégico nacional e internacional.

Entre las características socioculturales más relevantes de la población se encuentra el apego a costumbres arraigadas al patriarcado, cuyas formas más frecuentes de subordinación provienen de la desvalorización del trabajo doméstico femenino, del difícil acceso a los recursos productivos y del control masculino sobre sus cuerpos (González y Vizcarra, 2006; Vizcarra, 1997, 2002). Asimismo, la inequidad de género constantemente se ve reforzada, en cierta medida, por programas gubernamentales que consideran que el trabajo rutinario de las mujeres indígenas es extensible y adaptable. Así las cosas, la mayor parte de las propuestas para incorporar a las mujeres mazahuas en programas y proyectos gubernamentales se basan en aumentar sus ya de por sí numerosas actividades domésticas, mismas que han provocado su sumisión y desvalorización social (Pineda et al., 2006).

Ciertamente, hasta hace algunos años la reproducción social de los hogares se basaba en el autoconsumo de maíz -cultivado durante la temporada de lluvia-, en actividades de traspatio y en ingresos provenientes del trabajo extraagrícola de los varones y jóvenes mujeres que desde hace años emigran a las ciudades mexicanas para trabajar en la construcción, el comercio ambulante y el servicio doméstico (Vizcarra, 2002). Sin embargo, en la actualidad las mujeres rurales e indígenas se encuentran en un proceso de transformación de sus vidas cotidianas debido a diversos fenómenos que afectan el campo mexicano y que están estrechamente relacionados con el modelo económico neoliberal que conlleva el retiro paulatino del Estado de la política de desarrollo agropecuario y rural. Una consecuencia de este retiro se observa en el incremento de los flujos migratorios de varones, y recientemente de mujeres jóvenes, hacia los Estados Unidos y Canadá (Vizcarra y Guadarrama, 2006).

La creciente migración internacional ha intensificado el papel de las mujeres de esta región como cuidadoras, pues ahora se ven obligadas a hacerse cargo de los bienes de sus esposos, hijos, 
padres y hermanos. Asimismo, en ausencia de los gestores, confrontan nuevos procesos de negociación y toma de decisiones en cuestiones agrarias, productivas y ambientales. De ahí la importancia de estudiar la relación y percepción que tienen de las instituciones encargadas de apoyarlas, y no sólo porque ellas son parte de una política social que responde a las exigencias mundiales de incorporar al género femenino al desarrollo, sino porque algunas acciones gubernamentales institucionalizaron las demandas que las mujeres indígenas pusieron en la mesa de negociaciones en medio del conflicto zapatista de los años noventa (Pineda et al., 2006).

\subsection{Un capital social femenino "incómodo"}

Como influencia del levantamiento zapatista, vale la pena mencionar la reciente movilización de mujeres mazahuas en defensa del agua. Este movimiento indígena tiene sus orígenes desde los años setenta, y aunque las mujeres no eran protagonistas, como pueblo reivindicaban sus identidades y culturas colectivas. En 1981 algunas mujeres mazahuas se reunieron en San Felipe Santiago, municipio de Villa de Allende, con el propósito de organizar el Frente de Mujeres Mazahuas para exigir sus derechos. La reciente conformación del Ejército de Mujeres Mazahuas Zapatistas (EMMZ) en defensa del agua dio sus primeros brotes públicos a principios del 2004. Aun cuando las mujeres portan armas de fuego de madera, este movimiento más que violento es simbólico, basado principalmente en el capital social femenino indigena; es decir, en su capacidad organizativa para poner en marcha tácticas de lucha radical para defender los recursos naturales valiosos para su subsistencia.

No obstante que se trata de una lucha femenina, sus demandas se insertan en el discurso del desarrollo rural sostenible equitativo y justo, más que de género. Este movimiento busca reivindicar al pueblo indígena mazahua: ser tratadas con equidad; servicios para las comunidades, entre ellos agua, drenaje y electrificación; respeto al medio ambiente, por lo que solicitan un programa rural sostenible para la región; y, finalmente, reclaman la extracción de agua de la región, mediante el Sistema Cutzamala, que es llevada a la Zona Metropolitana de la Ciudad de México.

La primera ronda de negociaciones, en abril del 2004, entre comandantas mazahuas y representantes de instituciones gubernamentales a cargo de las políticas ambientales, forestales y de 
desarrollo rural (Semarnat, Conafor, CNA, Probosque, Sagarpa y otras instancias estatales), tuvo lugar en las comunidades Los Berros y Cerro del Salitre, en Villa de Allende, Estado de México, y la segunda tuvo lugar en las oficinas centrales de la CNA en la ciudad de México. Se firmaron algunos acuerdos en materia de infraestructura (construcción de invernaderos, ollas de captación de agua y pavimentación de accesos viales), introducción de servicios (instalación de letrinas secas, agua potable y energía eléctrica), pago de indemnización por daños a sus tierras, dotación de maquinaria y herramienta agrícolas, así como un extenso programa de reforestación. Pero hasta mediados de 2006, el EMMZ todavía sigue esperando que se cumplan cabalmente estos acuerdos. Es importante resaltar no sólo el activismo de las mujeres en la lucha por un acceso equitativo a los recursos indispensables para la subsistencia cotidiana de sus familias, sino también la actitud de indiferencia institucional al retardar el cumplimiento de los acuerdos. Tal vez este capital social femenino incomoda a las instituciones que no pueden sujetarlas a un esquema de política pública venida de arriba. Por otra parte, esta indiferencia también se puede explicar en el plano de las construcciones culturales de género, clase y etnia, donde no es creíble que exista esta capacidad de respuesta femenina, indígena y pobre, por eso no logran entender cómo algo tan vital para las mujeres indígenas como el agua, el bosque y la luz puede generar un conflicto social de esa envergadura.

Si bien las comunidades seleccionadas para el estudio, así como los municipios a que pertenecen, no están integradas ni se sienten representadas en este movimiento -aun cuando se encuentran en la misma franja forestal y una de las comunidades de estudio (La Mesa) forma parte del Área Natural Protegida de la Mariposa Monarca (ANPMM), donde se ubican algunas comunidades en lucha-, los acuerdos a que han llegado el EMMZ y las instancias gubernamentales pueden tener, en un futuro, implicaciones indirectas en la vida de las mujeres rurales e indígenas de la región.

\subsection{El vivero forestal social de La Mesa sin capital social femenino}

El municipio de San José del Rincón es de creación política-administrativa reciente. Hasta el 1 de enero de 2002, sus comunidades pertenecían al municipio de San Felipe del Progreso, pues como éste era el segundo más grande del Estado de México, no 
había un reparto uniforme de los recursos económicos (presupuestales) para todas las comunidades. Las 124 comunidades que ahora conforman San José del Rincón eran, por consiguiente, de las más desfavorecidas de la zona, además de que allí se concentra la mayor parte de población HLIM. ${ }^{16}$

San José del Rincón se encuentra a 2,760 msnm, con una superficie aproximada de 494,917 $\mathrm{km}^{2}$ y un área forestal de 12,475 ha. Dieciséis de sus comunidades son eminentemente forestales y forman parte del ANPMM o, como se le conoce comúnmente, el Santuario de la Mariposa, donde se encuentran especies forestales como pino pátula, pino montezumae, oyamel, ayacahuite y encino.

A este municipio pertenece la comunidad de La Mesa, cuya población aproximada es de 1,000 habitantes, de los cuales más de 55\% son mujeres. En la tercera ampliación de la resolución presidencial del 13 de marzo de 1980, esta población contaba con 752 ha de superficie ejidal. Pero en noviembre del 2000 se decretó un aumento a la Reserva de la Mariposa Monarca (que antes contaba con 16,000 ha entre Michoacán y el Estado de México) con lo que se incrementó a 56,000 ha entre las zonas núcleo y de amortiguamiento.

El 9 de febrero de 1952 se hizo una solicitud de 122 ejidatarios y se vino a resolver hasta el 8 de febrero de 1980. Peleamos con el multimillonario Tomás de la Fuente Casan, dueño de la hacienda Yondecé, predio Yondecé; cuando se ganó el ejido, aquí, allá en la loma y en el monte alto se acabó su poderío. Entonces, con la resolución presidencial se nos quedó el predio para cuidarlo, donde está el santuario son 752 ha. Yo estuve preso en Ixtlahuaca porque este señor nos malinformó que no era resolución presidencial, que era despojo de tierra; demandaron al presidente José López Portillo y a Antonio Toledo Corro de la Secretaría de la Reforma Agraria, y nosotros fuimos los terceros perjudicados. Estuve 24 horas. Gracias a que llevaba los documentos me soltaron, fuimos cinco a la cárcel. ${ }^{17}$

Debido a esta afectación, la Conafor promovió viveros sociales con el objetivo de dar fuentes de empleo a los dueños y poseedores de bosques, y así amortiguar el efecto de la ampliación sobre terrenos de 16 ejidos del municipio, que de por sí ya tenían su propia historia de desigualdad. "Y se dice afectados por decir algo, ya que no se pueden hacer aprovechamientos forestales como

\footnotetext{
${ }^{16}$ Según datos del Plan de Desarrollo Municipal (2003-2006), en el año 2000 el municipio estaba conformado por 74,874 habitantes, de los cuales alrededor de $70 \%$ es de origen mazahua.

${ }^{17}$ Entrevista con el comisariado ejidal, en junio de 2003.
} 
antes, sin restricciones, sólo con la normatividad de ley [...] ahora de octubre a marzo no se puede hacer nada porque es cuando llega la mariposa". ${ }^{18}$

En 2003 se implementaron dos viveros en la zona (de los 12 con que cuenta el estado), sin embargo, el único que sobrevive es el de La Mesa. Este vivero da seis empleos permanentes ocupados por hombres que perciben salario mínimo, y tiene una capacidad productiva de 500,000 plantas. Aunque para 2004 se preveía una producción de 45,000 plantas de oyamel en envases de $9 \times 20 \mathrm{~cm}$ para la reforestación anual en la zona del Santuario, por la poca cantidad de trabajadores sólo lograron producir $60 \%$ de la demanda. En aras de restaurar la zona núcleo de la ANPMM, el invernadero está altamente tecnificado, con malla media sombra, un robot para riego por aspersión y mesas para colocar charolas con 60 cavidades cada una. Estas charolas facilitan el traslado ya que en bolsas de $9 \times 20 \mathrm{~cm}$ se transportan 3,000 plantas en una camioneta, mientras que con las charolas aumenta a 5,000, con la ventaja de que las plantas no se contaminan con las bolsas y las charolas se utilizan otra vez. En este tipo de producción, las charolas se preparan con tierra a base de tecata y corteza de pino, que se compra ya elaborada por lo que no se ocupa tierra del bosque.

Es obvio que la infraestructura del invernadero no ha generado los empleos suficientes para compensar las restricciones del uso y manejo de los recursos forestales que dejaron de explotar, y que lo que menos requiere el vivero es mano de obra femenina y tampoco sus saberes tradicionales para producir plantas. Sin embargo, con el fin de acceder a los recursos federales etiquetados con perspectiva de género, la Conafor informa a la Semarnat que este proyecto beneficia directamente a las mujeres.

El bosque es de ámbito masculino mazahua, donde los hombres prohíben a las mujeres ir al bosque a buscar leña para uso doméstico; ellas sólo van a la orilla para recolectar hongos y plantas comestibles y medicinales. Ni cuando los hombres tenían acceso libre a él, las mujeres tenían derecho al usufructo del uso masculino de los recursos forestales maderables. Ellas únicamente podían obtener la leña a través de los hombres. Esto explica que las mujeres no sean invitadas a colaborar en el vivero, y si lo son, sus esposos o los mecanismos que regulan el acceso a los recursos (como la vigilancia que hacen otras mujeres y hombres del buen comportamiento femenino), no permiten su participación.

${ }^{18}$ Entrevista en junio del 2003 con el segundo regidor de la Comisión de Ecología y ejidatario de La Mesa. 
La carga de leña que me trae mi esposo me dura tres o cuatro días, según. Si se va a trabajar fuera de aquí y se tarda, entonces la tengo que comprar. No sé de dónde la traen, pero ellos lo saben para no meterse en problemas con la ley. Pues cada año va mi esposo e hijos a plantar al monte. Yo me quedo haciendo mi quehacer o hilando lana, o moliendo, o tejiendo una sábana, o faja de rancho, o tiñéndola con una plantita del bosque que da el rojo y consigo por ahí. ${ }^{19}$

Yo voy por la leña al bosque, ni modo que vaya mi mujer [...] La usamos sólo como combustible para la casa porque el gas está muy caro y las tortillitas no saben igual. [...] Ella se queda en casa, también recolectamos hierbitas como el nabo, chuales (quelite cenizo) y otro que le llaman el quintonil, ahora en época de lluvias empiezan los hongos enchiladitos, clavos orejas, cornetas. Se acaba esta temporada y siguen los gachupines, tejemanileros [...] y se acaban los hongos en octubre. [...] Aquí plantamos como 300 arbolitos cada persona de la variedad oyamel en el bosque donde está la mariposa, aquí en la comunidad muy poco, casi nada, todo es para allá arriba. [...] Sólo a las viudas por ley les dan sus arbolitos para plantar, pero ni modo que ellas vayan para allá, entonces le dan sus tortillas a los chamacos para que planten por ellas. Y en época de secas soy voluntario para los incendios, nos pegan el grito y todos los que estemos por aquí vamos, nos hacen nuestro itacate o tortillitas si hay y allá comemos. ${ }^{20}$

Los hombres de esta comunidad solicitaron apoyo a la Conafor para cambiar sus parcelas agrícolas por plantaciones comerciales forestales (en 2004 se encontraba en dictamen). Asimismo, el líder del proyecto del vivero social y regidor de la Comisión de Ecología de entonces (2003), acudió a diferentes dependencias y organizaciones para solicitar un apoyo económico, entre ellas la World Wide Found (WWF), de 16 dólares por metro cúbico, cantidad que consideran han dejado de aprovechar en el santuario. De este mismo fondo se obtuvo una ayuda de 50,000 pesos para el primer año (2003) con el fin de conservar el bosque, y esperan que el apoyo continúe. Otro organismo internacional que también otorga donaciones a la comunidad es Bosque Modelo Mariposa Monarca, A. C., financiado por el gobierno canadiense.

En cuanto a la Semarnat, Probosque y la Conafor, tienen un programa de protección que da empleo temporal y consiste en cercar con alambre de púas y posteo parte del bosque protegido, sobre todo el camino al santuario para que el ganado no entre a pastorear. De este mismo arreglo institucional existe un proyecto llamado Centro Ecoturístico Mariposa Monarca La Mesa en el paraje Torrecillas, donde ya funcionan dos de las diez cabañas

\footnotetext{
${ }^{19}$ Entrevista a la señora Lorenza, de 75 años, junio de 2003.

${ }^{20}$ Entrevista con don Federico, 62 años, junio de 2003.
} 
planeadas para ofrecer servicios de hospedaje rústico en la zona de amortiguamiento del Santuario de la Mariposa.

Cabe mencionar que en todos los apoyos institucionales, estatales, federales e internacionales que recibe esta comunidad, están incluidas las mujeres como beneficiarias directas e indirectas; sin embargo, los empleos que generan estos proyectos los ocupan hombres, mientras ellas siguen realizando los trabajos asignados a su género -que habitualmente no son recompensados económicamente porque se consideran poco importantes-: la limpieza de las cabañas y el vivero y la preparación de la comida para los trabajadores del mismo.

En cuanto a su capital social, se sabe que como parte de las costumbres mazahuas, las mujeres sólo se organizan para preparar alimentos y adornar las capillas durante las fiestas del santo patrón y otras ceremonias relacionadas con el sistema de cargos (Vizcarra, 2002). Se podría decir que las redes sociales femeninas se establecen sólo bajo las pautas de las relaciones de género que predominan en el pueblo mazahua: "las mujeres a la casa y los hombres a la milpa, al bosque y al espacio público”.

\subsection{Tapaxco, con capital social femenino y sin proyecto forestal}

El municipio del El Oro de Hidalgo fue uno de los más importantes hasta principios del siglo xx. Por la explotación minera de oro y de carbón vegetal desarrolló periodos de auge económico en la región. Si bien este municipio forma parte de la región mazahua, la colonización extranjera para la explotación de minerales y de haciendas agrícolas y pecuarias, provocó un importante proceso de mestizaje, hecho que se refleja en la escasa población de HLIM. El municipio cuenta con 30,396 habitantes de los cuales 15\% es HLIM (56\% mujeres) (González y Vizcarra, 2006).

El municipio se localiza en la parte montañosa del Estado de México y forma parte de la Sierra Madre Occidental, por lo que está rodeado de cerros, entre los más importantes: La Somera, en cuya vertiente se alza la cabecera municipal, hacia el sureste de ésta se encuentra el Cerro Llorón, segundo en importancia; la Carbonera en Tapaxco; y el de la Tijera en Basoco, de donde se extraía el carbón vegetal. Poco a poco se fueron cerrando las fuentes de explotación minera y con ello se redujeron enormemente las áreas boscosas. En la actualidad 36.8\% del territorio municipal es agrícola y se utiliza para cultivo de temporal; $7.6 \%$ es de uso 
pecuario; $21.3 \%$ (aproximadamente 2,947 ha) es forestal y $34.3 \%$ lo ocupan viviendas, comercios, oficinas y espacios públicos. De la superficie total, 9,161 ha son ejidales y 388 , comunales. ${ }^{21}$

Con el aumento reciente de la emigración transnacional, el municipio ha tenido un cierto crecimiento económico debido a las remesas que los paisanos envían regularmente a sus familias. De hecho, en la cabecera municipal se observa el aumento de actividades comerciales, así como bancos y casas de cambio.

En la comunidad de Tapaxco se encuentra la Carbonera, de la que dependían muchas familias hasta los años treinta del siglo Xx. Con el reparto de tierra durante los años cincuenta, las familias se dedicaron al monocultivo de maíz para autoconsumo y a la explotación de madera del bosque y, en menor proporción, de carbón vegetal. Dada la relativa cercanía con la cabeceara municipal (12 km aproximadamente) y el fácil acceso vial, otra actividad que ha crecido, por la necesidad de ingresos extraagrícolas, es el comercio y los servicios de transporte (taxis colectivos).

La comunidad está conformado por 17 barrios y cuenta con 396 habitantes, de los cuales la mayoría son mujeres y muy pocas hablan aún la lengua mazahua. Cuenta con prácticamente todos los servicios (excepto drenaje): agua, luz, escuelas y pavimentación y alumbrado público en las calles principales. Son pocas las familias que recolectan leña $-y$ las que lo hacen, la obtienen de árboles secos- que utilizan para preparar las tortillas de consumo diario. Hoy en día, la mayoría de los hogares usan gas como combustible. Esta población cuenta con un bosque en el cerro Andamejé en el que se encuentran especies de cedro, ocote, roble, encino, madroño, aile y pendicua. Para cortar un árbol del bosque, se requiere un permiso por escrito del delegado, quien no cuenta con éste, se hace acreedor a una multa o se le obliga a realizar trabajos en la comunidad.

Según un informante de la comunidad, desde que comenzó la administración del presidente Fox no ha habido grandes programas de reforestación. Sin embargo, según mujeres con quienes conversamos, cada año ellas y algunos hombres forman parte de la campaña de reforestación, en la que también participan sus hijos en la escuela, aunque también denunciaron que cada vez se plantan menos árboles porque los resultados no son muy alentadores: "Sí, cada año vamos al cerro de Endotejeare. Viene el

${ }^{21}$ Los datos se obtuvieron directamente de la entrevista sostenida con el encargado de asuntos agrarios del municipio en 2004. 
ejército a ayudarnos y plantamos como mil arbolitos" (Virginia de 26 años, entrevistada en mayo de 2003). "Luego voy a plantar arbolitos con los de la comunidad, cuando hay. Pero ya no, los chamacos los tiran, los queman y mejor ya no plantamos nada" (Sonia de 43 años, entrevistada en mayo de 2003).

El tejido social de la comunidad se basa en el trabajo colectivo de las mujeres, quienes han fortalecido los lazos de cooperación frente al fenómeno de migración masculina nacional y transnacional. El trabajo colectivo femenino se ha reforzado sobre todo a través de actividades de la Iglesia católica. Así, las mujeres se organizan no sólo para las celebraciones religiosas, también participan en diferentes eventos políticos, y con frecuencia envían representantes a buscar apoyos para proyectos productivos ante diferentes instancias no gubernamentales (principalmente). La presencia femenina en la vida de la comunidad condujo a que un ama de casa, esposa de un taxista, fuera electa como la primera mujer delegada municipal; lo que dio pie a que cada vez más mujeres formen parte de los comités de vigilancia de alguna obra en construcción o de cualquier otro asunto que beneficie a la comunidad.

Cuando se hacía la reforestación, aquí en la comunidad somos muy unidos y organizados y raro es el que no participa; la delegada es la que nos organiza y también hay un comité de obras. Para fiestas religiosas se organizan todas las comunidades de Tapaxco, cuando es fiesta en la parroquia los fiscales son los que se encargan de eso. El comité lo forma el presidente que es un hombre y todas las demás son mujeres, lo decidimos así para que la gente que no apoya a las mujeres se dé cuenta que las mujeres tienen mucho que ver. También hay un comisariado ejidal que vigila todo lo relacionado con el campo, por ejemplo, que se cierren bien las compuertas de las presas, como la de San Isidro, la Cañada, las Golondrinas, las Arenas y la de las Manzanas. ${ }^{22}$

\section{Consideraciones finales}

Frente a la degradación ambiental y la desigualdad social y de género se han desarrollado diferentes propuestas teóricas y políticas que apuntan, en general, a reconocer que estos problemas conllevan intereses económicos de orden mundial. En este proceso de globalización es inevitable la conexión entre economía y medio ambiente, al tiempo que la degradación de los ecosistemas se vincula con los grandes problemas socioculturales como la pobreza,

\footnotetext{
${ }^{22}$ Joaquín, 48 años, entrevistado en mayo de 2003.
} 
el hambre, la migración, la producción de energía, los asentamientos urbanos, la violencia, la inseguridad social, la violación de los derechos humanos y las desigualdades entre los géneros, las razas, las etnias, las clases, las regiones y las generaciones.

Pero el mayor reto de confrontar la economía política con la ecología es entender en qué nivel de la construcción de los problemas se definen las demandas sociales, en las que una vez difundidas como prácticas discursivas, se legitima la necesidad de intervenir institucionalmente para atenderlas y darles solución. Dónde y cómo se diseñan las políticas y programas, qué mecanismos externos e internos se desarrollan para que se instrumenten y ejecuten, cómo funcionan y cuáles son las respuestas que se generan entre las instituciones y las poblaciones objetivos de estos programas, son preguntas que se pueden responder a través de las etnografías institucionales, tal es el propósito de este trabajo. Es decir, logramos observar cómo se incluyeron el concepto de capital social y la perspectiva de género en el diseño de las políticas ambientales forestales del gobierno de Vicente Fox; asimismo, analizamos que la ejecución de éstas tuvo serias limitantes en contextos locales de la región mazahua, lo que generó resultados imprevistos del objetivo inicial, sobre la idea de que a mayor capital social femenino más éxito en la inclusión de las mujeres al desarrollo sostenible y, por tanto, una mejora sustancial en las condiciones de vida de éstas, su familia y las comunidades.

En los discursos oficiales se reconoce que las mujeres campesinas-indígenas son las más afectadas por la crisis del campo mexicano y por la degradación ambiental (Vázquez, 1999). A pesar de ello, las políticas ambientales, forestales y de equidad de género responden principalmente a los grandes acuerdos y compromisos firmados en convenciones internacionales. En este contexto, el Estado mexicano se esfuerza institucionalmente para dar salida a dichos compromisos, pero aún no hay una presencia de mujeres en los programas, ni como actoras sociales ni como promotoras de cambio. En efecto, pese a la preocupación de la Semarnat, expresada a través de sus funcionarias en el sentido de que "no puede darse un desarrollo sostenible sin la participación de hombres y mujeres, con igualdad de oportunidades en su relación con los recursos naturales", observamos que no es suficiente que algunas mujeres con conciencia feminista estén en puestos clave en la toma de decisiones para instrumentar políticas ambientales con perspectiva de género. Falta mucho para 
entender que mientras las estructuras políticas y las actitudes culturales no adopten una perspectiva de género equitativa en políticas ambientales, seguiremos bajo controles sociales de orden patriarcal.

Es posible señalar que cuando las demandas sociales se formulan en ámbitos internacionales y los Estados-nación las adoptan como una práctica de buena voluntad para mejorar las condiciones de las mujeres, en general lo que pretenden es traducir, maquillar y adecuar las demandas reales para que concilien con las acciones implícitas del desarrollo, organizadas de arriba hacia abajo y de afuera hacia adentro. Estas ideas fueron abordadas en la etnografía institucional del Progemas en las comunidades mazahuas del Estado de México. Así, encontramos que en el diseño e instrumentación de la política ambiental-forestal, las mujeres pobres e indígenas fueron utilizadas políticamente para acceder a los recursos financieros de las agencias internacionales de desarrollo, pues en la ejecución de los programas, ellas prácticamente no aparecen como sujetos sociales.

De acuerdo con lo anterior, la comunidad de La Mesa no responde al diseño de las políticas ambientales porque no cuenta con capital social femenino, como lo requiere la misma política, y tampoco es de interés o prioridad ambiental nacional o internacional debido a que se ubica en el Área Natural Protegida de la Mariposa Monarca, donde se ejecutan proyectos forestales, ecoturísticos y de conservación del santuario con perspectiva de género, pero sólo con el afán de conseguir financiamientos. Sin embargo, dadas las construcciones sociales sobre relaciones de género, las mujeres mazahuas de La Mesa no tienen acceso a los recursos naturales ni a los proyectos y tampoco a los beneficios de éstos. En cambio la comunidad de Tapaxco cuenta con un elevado capital social femenino, con el que las mujeres participan activa y socialmente en diversos proyectos colectivos en provecho de su comunidad y de sus familias, pero no existe un interés explícito institucional por emplear este capital para llevar a cabo proyectos forestales que generen beneficios materiales directos a ellas y sus familias, con excepción de las pocas áreas donde se llevan a cabo trabajos de reforestación como parte de las campañas nacionales. Por otro lado, cuando el capital social femenino incomoda a las instituciones gubernamentales, como en el caso del EMMz, lo marginan o recibe un trato especial con el fin de incorporarlo a los mecanismos de control social donde cambie de tono político, de rebelión o conflicto, a programa exitoso. 
No queda claro cómo la incorporación de capital social y género en las políticas ambientales-forestales puede convertirse en mecanismos de control sobre los recursos naturales considerados de seguridad nacional (como el agua y las áreas forestales), sobre todo cuando éstos se encuentran en territorios estratégicos para el desarrollo económico del país. Sin embargo, es posible formular nuevas hipótesis de trabajo si se considera, por ejemplo, el especial interés de los programas gubernamentales por promover proyectos productivos y ambientales (incluidos los forestales) sólo con grupos organizados que capitalicen su participación social en un bien público. Interés que puede tener un trasfondo político y de control social que sólo se muestra en el éxito de sus programas y proyectos a través de indicadores económicos y de número de beneficiados.

Se puede abordar otra hipótesis desde la economía política feminista, pues como se observó en este estudio, el trabajo de las mujeres es subestimado junto con los recursos naturales. Puesto que el trabajo doméstico que realizan las mujeres y los campesinos para subsistir, el bienestar, la paz y el equilibrio del medio ambiente no son actividades que se relacionan con la producción y el mercado, carecen de valor y por tanto no se les da la importancia trascendente que tienen en la economía política. Si bien la conservación del medio ambiente requiere la participación completa de los miembros de las comunidades, hombres y mujeres, necesitamos aprender a interpretar las verdaderas demandas sociales relacionadas con la naturaleza y la subsistencia misma, las cuales son muy diferentes a los valores que impone el mercado, hasta el punto que pueden llegar a estar en conflicto, pero no por ello dejan de ser reales ni menos importantes.

Finalmente, otra línea de trabajo es sin duda la necesidad de reconceptualizar las nociones de desarrollo rural sostenible, capital social e, incluso, igualdad de género. Ya que, por ejemplo, el capital social femenino como recurso institucional aparece sólo cuando los hombres están ausentes, entonces cabe preguntarnos, ¿este capital no existe cuando los hombres desarrollan actividades económicas en la comunidad? Tal vez una mayor comprensión de los conceptos y realidades complejas en los diferentes niveles de gobierno pueden llegar a promover la creatividad institucional para atender las demandas sociales reales, sin generar diferencias y desigualdades sociales. 


\section{Bibliografía}

Acosta E., Nelson (2002), "Cultura y política en América Latina”, Convergencia, 29, Universidad Autónoma del Estado de México, México, pp. 127-150.

Agarwal, B. (1994), "The Gender and the Environment Debate: Lessons from India”, en L. Arizpe, O. Stone y D. Major (eds.), Population and Environment: Rethinking the Debate, Westview Press, San Francisco, pp. 87-124.

Aranda Sánchez, José María (2005), "Importancia de las mujeres en la construcción del movimiento ambientalista en México", en Ivonne Vizcarra B. (coord.), Género y poder: diferentes experiencias, mismas preocupaciones, Universidad Autónoma del Estado de México, México, pp. 159-180.

Arizpe, Lourdes, Fernanda Paz y Margarita Velázquez (1993), Cultura y cambio global: percepciones sociales sobre la deforestación en la selva lacandona, Porrúa-CRIM-Universidad Nacional Autónoma de México, México.

BID (Banco Interamericano de Desarrollo) (2001), Iniciativa interamericana de capital social. Ética y desarrollo, en $<$ www.iadb.org/etica/index/cfm/>, 5 de abril de 2004.

BM (Banco Mundial) (2001a), “¿Qué es el capital social?” Poverty Net, Washington, en <www.worldbank.org/poverty/ spanish/scapital>, noviembre de 2001.

BM (2001b), “¿Por qué es el capital social importante para el desarrollo?" Poverty Net, Washington, en <www.worldbank. org/poverty/spanish/scapital/scwhyrel1.htm>, noviembre de 2001.

Birke, Lynda (1986), “Developing Gender”, en Linda Birke (coord.), Women, Feminism, and Biology, The Feminist Challenge. Methun, Nueva York, pp. 75-88.

Bourdieu, Pierre (1986), "The Forms of Capital (R. Nice, Trans.)", en John Richardson (ed.), Hanbook of Theory and Research for the Sociology of Education, Nueva York, Greenwood Press, pp. 241-258. 
Braidotti, Rosi, Ewa Charkiewicz, Sabine Häusler y Saskia Wieringa (1994), Women, the Environment and Sustainable Development. Towards a Theatrical Synthesis, Zed BooksINSTRAW, Londres.

Brundtland, Gro Harlem (1987), “Comisión Mundial sobre el Medio Ambiente y Desarrollo (CNUED). Nuestro futuro común”, Reporte de la Comisión Mundial sobre Medio Ambiente y Desarrollo, Noruega.

CEMPaem (Centro de Estudios sobre Marginación y Pobreza del Estado de México) (2004), "Identidad, capital social y potencial de desarrollo", Marginación y pobreza. Cuadernos para el desarrollo social, año 2, 5, Secretaría de Desarrollo Social-Gobierno del Estado de México, México, 80 pp.

CEPAL (Comisión Económica para América Latina y el Caribe) (2003), Capital social y reducción de la pobreza en Latinoamérica y el Caribe: en busca de nuevos paradigmas, CEPAL, Santiago de Chile.

Clifford, James (2000), "El surgimiento de la antropología postmoderna", en Carlos Reynoso (comp.), La antropología postmoderna, Gedisa, Barcelona.

Coleman, James (1990), Foundations of social theory, Belk Press, Cambridge.

Durston, John (1999), "Construyendo capital social comunitario", Revista de la CEPAL, 69, Oficial de Asuntos Sociales, División de Desarrollo Social, CEPAL, Santiago de Chile, pp. 105-118.

Escobar, Arturo (1995), Encountering Development. The Making and the Unmaking of the Third World, Princeton, Princeton University Press.

FAO (Food and Agriculture Organization) (1997), Decreto por el que se reforma la Ley Forestal, México, <en http://www. fao.org/forestry/fo/country/index>, octubre de 2001.

FAO (2005), Situación de los bosques del mundo, FaO, Roma. 
Ferguson, James (1990), The anti-politics machine: "development" depoliticization and bureaucratic power in Lesotho, Cambridge University Press, Cambridge.

González Ortíz, Felipe e Ivonne Vizcarra Bordi (2006), Mujeres indígenas en el Estado de México. Vidas conducidas desde sus instituciones sociales, El Colegio Mexiquense, A. C.-Universidad Autónoma del Estado de México, México.

Lamas, Martha (2006), Feminismos: transmisiones y retransmisiones, Taurus, México.

Leach, Melissa, Susan Joekes y Cathy Green (1995), "Gender Relations and Environmental Change", International Development Studies Bulletin, 26(1), Institute for Development Studies, Reino Unido, pp. 1-8.

Lechner, Norbert (2000), "Desafíos de un desarrollo humano: individualización y capital social", Instituciones y Desarrollo, 7, Instituto Nacional de Gobernabilidad, Barcelona, en $<$ http://www.iigov.org/id/article.drt?edi=187626\& art $=187652>, 4$ de diciembre de 2003.

Lewis, David (2001), "La cooperación como proceso. Construcción de la etnografía institucional en Bangladesh”, Economía, Sociedad y Territorio, 3(10), El Colegio Mexiquense, A.C., México, pp. 355-377.

MacKenzie, Susan, J. Foord y M. Breibart (1984), "Antipode”, A Radical Journal of Geography, Blakwell Publishing, Manchester, 16(3), 3-10.

Merino, Leticia (2004), Conservación o deterioro. El impacto de las políticas públicas en las instituciones comunitarias y en los usos de los bosques en México, Semarnat-INE-Consejo Civil Mexicano para la Silvicultura, México, A. C.

Nahmad, Salomon (2001), "Estudio del impacto del Proyecto de Desarrollo Rural en Áreas Marginadas de la Sagarpa sobre el capital social y la identidad cultural", ponencia presentada en el tercer congreso Los actores sociales frente al desarrollo rural, Zacatecas, México. 
ONU (Organización de las Naciones Unidas) (1992), Conferencia sobre medio ambiente y desarrollo, Río de Janeiro, en $<$ www.mujer.gov.ar/dec17.htm>, 11 de julio de 2002.

ONU (2000), La mujer y el medio ambiente, conferencia, nota informativa11, Nueva York, en <www.un.org/spanish/conferences/Beijing/fs11.htm>, 7 de octubre de 2001.

Paolisso, Michael (1996), "Avances de la investigación sobre género y medio ambiente”, en Margarita Velázquez (coord.), Género y ambiente en Latinoamérica, Universidad Nacional Autónoma de México-Centro Regional de Investigaciones Multidisciplinarias (CRIM), México, pp. 241-261.

Pineda Ruíz, Siboney, Ivonne Vizcarra Bordi y Bruno Lutz Bachere (2006), "Gobernabilidad y pobreza: proyectos productivos para mujeres indígenas mazahuas del Estado de México", Indiana, Revista de Iberoamerika, núm. 23, Berlín, pp. 283-308.

Plan de Desarrollo Municipal de San José del Rincón (2003), Municipio de San José del Rincón 2003-2005, Estado de México, México.

Putnam, Robert (1993), "The Prosperous Community: Social Capital and Public Life", The American Prospect Inc., 13, Washington, D.C., <http://epn.org/prospect/13/13putn. html>, 12 de octubre de 2002.

PNUD (Programa de las Naciones Unidas para el Desarrollo) (2000a), Desarrollo humano en Chile. Más sociedad para gobernar el futuro, onu, Santiago de Chile.

PNUD (2000b), Informe sobre desarrollo humano, ONU, Santiago de Chile.

Rocheleau, Diana, Barbara Thomas-Slayter y Esther Wangari (1996), Feminist Political Ecology; Global Issues and Local Experiences, Routledge, Londres.

Salazar, Hilda (1999), "Mujer y medio ambiente: acuerdos internacionales”, en Verónica Vázquez G. (coord.), Géne- 
ro, sostenibilidad y cambio social en el México rural, Colegio de Posgraduados, México, pp. 179-191.

Semarnat (Secretaría de Medio Ambiente, Recursos Naturales y Pesca) (1999), "Declaración para la equidad de género", en <www.semarnap.gob.mx/gestion/documentos/ declara.htm>, abril de 2005.

Semarnat (2003), "Puntos fundamentales de la Nueva Ley General de Desarrollo Forestal Sustentable", documento interno, México.

Semarnat (2004), "Programa de Equidad de Género, Medio Ambiente y Sostenibilidad (2002-2006), documento interno, México.

Shiva, Vandana (1988), Staying Alive; Women, Ecology and Development, Zed Books Ltd, Londres.

Vázquez-García, Verónica (1999), “Género, medio ambiente y desarrollo sostenible: reflexiones teóricas y metodológicas", en Verónica Vázquez García (coord.), Género, sostenibilidad y cambio social en el México rural, Colegio de Posgraduados, México.

Vázquez-García, Verónica (2002), ¿Quién cosecha lo sembrado? Relaciones de género en un área natural protegida mexicana, Plaza y Valdés-Colegio de Postgraduados, México.

Velázquez G., Margarita (1996), "El uso y manejo de los recursos forestales desde una perspectiva de género. Una propuesta metodológica”, en Margarita Velázquez (coord.), Género y ambiente en Latinoamérica, Centro Regional de Investigaciones Multidisciplinarias (CRIM)-Universidad Nacional Autónoma de México, México, pp. 429-448.

Velázquez G., Margarita (1997), “Desarrollo y participación: el uso de los recursos naturales de bosques y selvas. Una aproximación desde la perspectiva de género", en Margarita Velázquez G. y Leticia Merino (coords.), Género, análisis y multidisciplina, Centro Regional de Investigaciones Multi- 
disciplinarias (CRIM)-Universidad Nacional Autónoma de México, Cuernavaca, Morelos. México, México, pp. 55-79.

Velázquez G., Margarita (2005), "El monte se va a acabar: las percepciones de hombres y mujeres acerca del futuro de la selva en la zona maya de Quintana Roo", en Paola Seisa y Emma Zapata (coords.), Transformaciones del campo mexicano: una mirada desde los estudios de género, t. 5, AMER-Conacyt-Gobierno de Zacatecas-Praxis, México, pp. 69-112.

Velázquez, Margarita y Leticia Merino (coords.) (1997), Género, análisis y multidisciplina, Centro Regional de Investigaciones Multidisciplinarias (CRIM)-Universidad Nacional Autónoma de México, México.

Vizcarra-Bordi, Ivonne (1997), "Transformaciones de las relaciones genéricas y generacionales en los sistemas de producción campesinos de la zona mazahua”, Ciencia Ergo Sum, 3(3), Universidad Autónoma del Estado de México, México, pp. 47-62.

Vizcarra-Bordi, Ivonne (2002), Entre el taco mazahua y el mundo: la comida de las relaciones de poder, resistencia e identidades, Universidad Autónoma del Estado de MéxicoGobierno del Estado de México, México.

Vizcarra-Bordi, Ivonne (2005), "El saber local ecológico femenino y la frontera científica”, en Norma Blázquez G. y Javier Flores (comps.), Ciencia, tecnología y género en Iberoamérica, Universidad Nacional Autónoma de México-Universidad Femenina-Plaza y Valdés, México, pp. 543-560.

Vizcarra-Bordi, Ivonne y Xóchitl Guadarrama R. (2007), “Qué ganan y qué pierden las mujeres mazahuas con el Programa Oportunidades cuando los hombres emigran", en Memorias XXVIII International Congress of the Latin American Studies Association (LASA), Montreal, 22 p. 
Recibido: 1 de junio de 2006. Reenviado: 08 de noviembre de 2006. Reenviado: 12 de diciembre de 2006. Aceptado: 13 de diciembre de 2006.

Silvana Lara Aldave. Es maestra en ciencias agropecuarias y recursos naturales por la Universidad Autónoma del Estado de México. Actualmente está adscrita al Centro de Investigación en Ciencias Agropecuarias de la mencionada universidad. Sus líneas de investigación son: género y medio ambiente.

Ivonne Vizcarra Bordi. Es doctora en antropología social por la Universidad Laval, Québec, Canadá. Está adscrita al Centro de Investigación en Ciencias Agropecuarias de la Universidad Autónoma del Estado de México; es presidenta de la Asociación Mexicana de Estudios Rurales A. C. Sus líneas de investigación se centran en: género, migración, governance, etnografía institucional, seguridad alimentaría y desarrollo rural. Entre sus publicaciones destacan: "The 'Authentic' Taco and Peasant Women: Nostalgic Consumption in the Era of Globalization", Culture \& Agriculture Fall, 28(2), pp. 97-107 (2006), en coautoría con Felipe González Ortiz, Mujeres indígenas del Estado de México. Vidas conducidas desde sus instituciones sociales, México, El Colegio Mexiquense, A.C.-Universidad Autónoma del Estado de México, 247 pp. (2006); en coautoría con Nadia Marín Guadarrama, "Las niñas a la casa y los niños a la milpa: la construcción social de la infancia mazahua", Convergencia, año 13, 40, Universidad Autónoma del Estado de México, México, pp. 39-68 (2006). 